MOURÃO, R.C. et al. Processamento do milho na alimentação de ruminantes. PUBVET, Londrina, V. 6, N. 5, Ed. 192, Art. 1292, 2012.

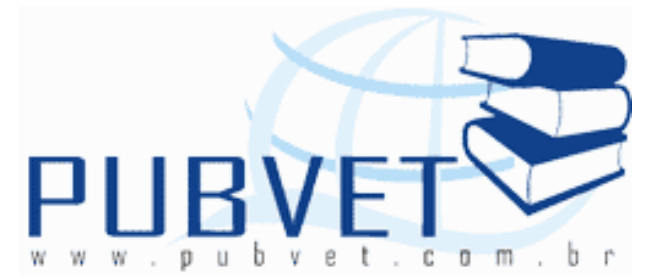

PUBVET, Publicações em Medicina Veterinária e Zootecnia.

\title{
Processamento do milho na alimentação de ruminantes
}

Raphael de Castro Mourão ${ }^{1}$, Carlos Giovani Pancoti ${ }^{1 *}$, André Moraes Moura ${ }^{2}$, Alexandre Lima Ferreira ${ }^{1}$, Ana Luiza da Costa Cruz Borges ${ }^{3}$, Ricardo Reis e Silva ${ }^{3}$

${ }^{1}$ Doutorando em Zootecnia, Departamento de Zootecnia, Escola de Veterinária, Universidade Federal de Minas Gerais, Brasil, Bolsista do CNPq.

${ }^{2}$ Mestrando em Zootecnia, Departamento de Zootecnia, Escola de Veterinária, Universidade Federal de Minas Gerais, Brasil

${ }^{3}$ Professor do Departamento de Zootecnia, Escola de Veterinária, Universidade Federal de Minas Gerais, Brasil

*E-mail para correspondência: cgpancoti@yahoo.com.br

\section{Resumo}

Em tempos de busca de tecnologias para aumentar a produtividade dos rebanhos sem, no entanto, onerar os custos de produção, os estudos envolvendo a maximização da eficiência digestiva em função da utilização de alimentos processados apresentam grande potencial. O processamento do grão de milho promove alterações no sítio de digestão do amido, no aproveitamento total do alimento e da dieta, além de proporcionar alterações substanciais no ambiente ruminal. Neste sentido, o objetivo desta revisão é apresentar os métodos de processamento do grão de milho, bem como as vantagens e 
MOURÃO, R.C. et al. Processamento do milho na alimentação de ruminantes. PUBVET, Londrina, V. 6, N. 5, Ed. 192, Art. 1292, 2012.

desvantagens destas técnicas, com foco na alimentação de ruminantes. Palavras-chave: amido, bovinos, digestibilidade, gelatinização.

\section{Processing corn in ruminant feed}

\section{Abstract}

In times of search technologies to improve livestock productivity without, however, charge the costs of production, studies involving maximizing digestive efficiency depending on the use of processed foods have great potential. The processing of corn promotes changes in the site of starch digestion, in the total utilization of food and diet, as well as providing substantial changes in the rumen. In this sense, the objective of this review is to present methods of processing corn, as well as the advantages and disadvantages of these techniques, focusing on the feeding of ruminants.

Keywords: starch, cattle, digestibility, gelatinization.

\section{INTRODUÇÃO}

No Brasil, a dieta de ruminantes é predominantemente composta por alimentos volumosos em pastagens, geralmente fazendo parte de sistemas de produção extensivos, onde é significativa a baixa disponibilidade de alimentos durante o período de estiagem. Segundo Valente (1991), as plantas forrageiras do Brasil Central, em qualquer sistema de pastejo, apresentam entre 75 e $85 \%$ da sua produção anual de matéria seca na época das águas, período quente e chuvoso, ocasionando com isto disponibilidade inconstante de forragem durante $o$ ano.

Frente à crescente demanda mundial por alimentos e à valorização constante da terra no país, a intensificação dos sistemas de produção de ruminantes parece ser uma tendência duradoura. Além dos fatores supracitados, a importância da conservação dos recursos naturais torna-se cada vez mais presente nas políticas governamentais e na consciência da sociedade, 
MOURÃO, R.C. et al. Processamento do milho na alimentação de ruminantes. PUBVET, Londrina, V. 6, N. 5, Ed. 192, Art. 1292, 2012.

incentivando o aumento da produção animal nas áreas já utilizadas para esta finalidade, para que sejam preservadas as áreas de florestas e respeitadas as divisas agropecuárias.

Neste sentido, o fornecimento de suplementação, constituída por alimentos volumosos ou concentrados, garante os nutrientes suficientes para que possam ser alcançados desempenhos produtivos capazes de viabilizar economicamente a produção de ruminantes. Entre as tecnologias disponíveis para alavancar o desempenho produtivo dos rebanhos, a utilização de grãos processados se destaca em função da possibilidade de alteração do potencial nutricional destes ingredientes sem, no entanto, elevar demasiadamente o custo de produção.

O milho é um cereal energético, chegando a conter ente 70 e $80 \%$ de amido na sua composição, com base na matéria seca (Rostagno et al., 2000). No entanto, parte deste amido não é degradada no rúmen, sendo muitas vezes perdida nas fezes, sem que seja digerida. Neste sentido, o aumento da exposição do amido à digestão ruminal é a principal vantagem do processamento do milho em dietas de ruminantes, a partir da ruptura da parede celular.

Existem diversas maneiras conhecidas e comprovadamente eficientes de se promover um melhor aproveitamento dos grãos, em especial do milho, a partir do seu processamento. Neste sentido, o intuito desta revisão é apresentar as formas mais comuns de processamento do grão de milho, bem como as vantagens e desvantagens destas técnicas, com foco na alimentação de ruminantes.

\section{REVISÃO DE LITERATURA}

\section{IMPORTÂNCIA DO MILHO NA ALIMENTAÇÃO DE RUMINANTES}

O milho ocupa um lugar de destaque no cenário nacional e mundial. Cerca de $80 \%$ dos grãos cultivados no país são constituídos pelo milho e pela soja, sendo que a produção do primeiro é direcionada principalmente para o mercado interno (Pereira e Antunes, 2007). No entanto, com o advindo dos 
MOURÃO, R.C. et al. Processamento do milho na alimentação de ruminantes. PUBVET, Londrina, V. 6, N. 5, Ed. 192, Art. 1292, 2012.

biocombustíveis e a destinação de boa parte da produção de milho norte americana para esta finalidade, abriu-se uma lacuna na oferta do grão no mercado internacional nos últimos anos. Desta forma, o crescimento da cultura do milho no Brasil e a sua participação no mercado externo têm aumentado a cada ano.

A alimentação animal é o destino de cerca de $50 \%$ do milho produzido no país, o que faz com que este insumo seja um importante contribuinte para a oscilação dos preços dos alimentos concentrados (Lima, 2001). Segundo este mesmo autor, do volume anual de milho consumido pela alimentação animal, a avicultura demanda $60,5 \%$ e a suinocultura $28,5 \%$, restando apenas $11,0 \%$ para a alimentação de ruminantes e outras espécies. No entanto, boa parte do milho destinado à alimentação humana é direcionada para a extração do amido, gerando vários subprodutos comumente destinados à alimentação de ruminantes.

\section{CARACTERÍSTICAS FÍSICAS DO MILHO}

A partir de um corte longitudinal em um grão de milho, pode-se verificar que este é formado por três partes: a primeira é o pericarpo ou casca, rico em fibras; a segunda é composta pelo endosperma, rico em amido, bem como pelo glúten, localizado mais internamente e rico em proteínas; e a terceira é o gérmen ou embrião, que é a parte vegetativa do grão, constituída principalmente por lipídeos e proteínas (Henrique e Bose, 1995). Segundo Paes (2006), existe ainda uma quarta estrutura chamada ponta, responsável por apenas $2 \%$ do grão e formada por material lignocelulósico.

Nutricionalmente, o endosperma é o componente mais importante do grão, sendo uma região de estocagem de energia e, em menor escala, de proteínas, enzimas, vitaminas e minerais. Esta porção constitui $82 \%$ do cereal e armazena $98 \%$ do amido presente no grão (Paes, 2006).

O gérmen representa aproximadamente $11 \%$ do grão de milho e concentra quase a totalidade $(83 \%)$ dos lipídios e minerais (78\%) do grão, além de 
MOURÃO, R.C. et al. Processamento do milho na alimentação de ruminantes. PUBVET, Londrina, V. 6, N. 5, Ed. 192, Art. 1292, 2012.

conter quantidades importantes de proteínas (26\%) e açúcares (70\%). Tratase de um componente de reserva de nutrientes para o embrião.

O pericarpo representa, em média, $5 \%$ do grão, conferindo proteção contra a umidade do ambiente, aos insetos e microrganismos. As camadas de células que compõem esta fração fibrosa são constituídas de hemiceluloses (67\%) e celuloses (23\%). A ponta é a menor estrutura do grão de milho, e é a responsável pela conexão entre o grão e o sabugo, sendo a única área não coberta pelo pericarpo.

\section{COMPOSIÇÃO QUÍMICA DO MILHO}

A composição química do grão de milho no Brasil se apresenta de maneira significativamente variável, sendo influenciada por fatores como genótipo, condições edafoclimáticas e de armazenamento. Na tabela 1 é apresentada a composição química média do grão de milho, segundo o NRC (2001) e Valadares et al. (2002).

Tabela 1: Composição nutricional do milho grão

\begin{tabular}{|c|c|c|c|c|c|c|c|c|c|c|c|}
\hline \multirow{2}{*}{ Fonte } & \multicolumn{11}{|c|}{ Nutriente } \\
\hline & MS & PB & $\mathrm{EE}$ & MM & FDN & FDA & NDT & $\mathrm{Ca}$ & $\mathrm{P}$ & Lys & Met \\
\hline NRC (2001) & 88,10 & 9,40 & 4,20 & 1,50 & 9,50 & 3,40 & 88,10 & 0,04 & 0,30 & 2,84 & 2,13 \\
\hline $\begin{array}{l}\text { Valadares et } \\
\text { al. (2002) }\end{array}$ & 87,78 & 9,10 & 4,18 & 1,66 & 14,39 & 4,28 & 86,03 & 0,03 & 0,25 & 2,84 & 2,13 \\
\hline
\end{tabular}

Comparados aos dados médios nacionais (Valadares et al, 2002), os valores de PB e de NDT apontados pelo NRC (2001) são ligeiramente superiores, e os valores de FDN e FDA inferiores, fato provavelmente relacionado à utilização de diferentes genótipos, bem como aos demais fatores ambientais já relatados. 
MOURÃO, R.C. et al. Processamento do milho na alimentação de ruminantes. PUBVET, Londrina, V. 6, N. 5, Ed. 192, Art. 1292, 2012.

\section{CLASSIFICAÇÃO E TIPOS DE GRÃOS DE MILHO}

Segundo Pereira e Antunes (2007), existem cinco classes ou tipos de milho: dentado, duro, farináceo, pipoca e doce (Figura 1). Nos países de clima temperado o tipo predominante é o milho dentado, enquanto no Brasil se destaca a classe de milho duro. Os demais tipos não são utilizados em larga escala, sendo que o milho pipoca é verificado em microrregiões dos trópicos e o farináceo algumas vezes nas regiões temperadas.

A principal diferença entre os tipos de milho é a forma e tamanho dos grãos, definidos pela estrutura do endosperma e o tamanho do gérmen. $O$ amido no endosperma do milho duro é quase todo rígido (também chamado vítreo), enquanto o milho farináceo tem praticamente todo seu amido como endosperma farináceo (Pomeranz et al., 1984). Híbridos de milho dentado apresentam uma parte do endosperma vítreo e outro farináceo, assim os híbridos de milho se diferem pela sua relação de endosperma vítreo: farináceo (Watson, 1987).

A diferença ultraestrutural mais importante entre os endospermas vítreo e farináceo é a menor concentração de matriz protéica no endosperma farináceo, que confere melhor acessibilidade às enzimas e maior digestibilidade (Hoseney et al., 1974).

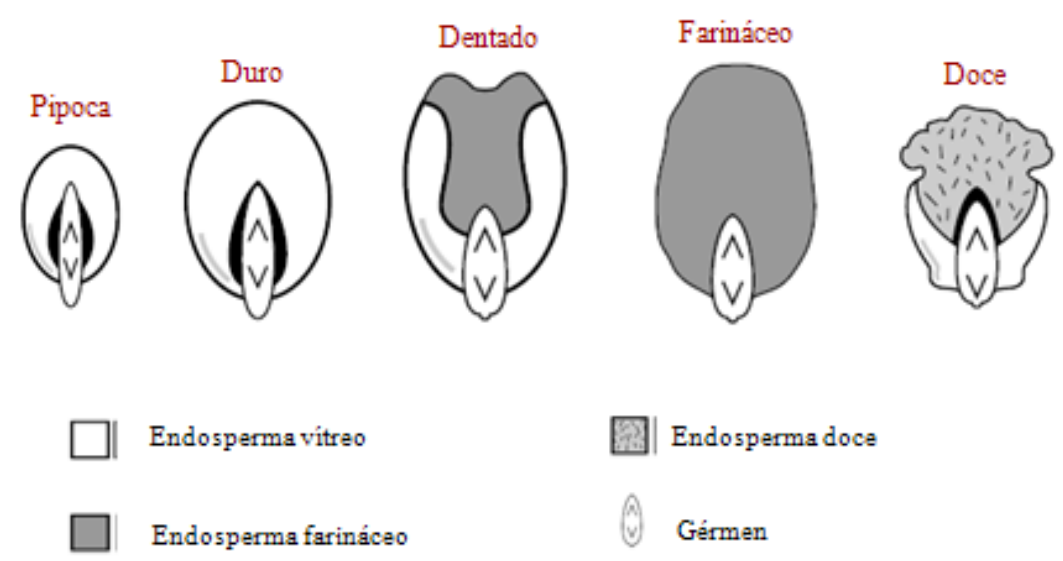

Figura 1: Classificação do milho quanto ao tipo de grão - estrutura do endosperma e tamanho do gérmen. Fonte: Adaptado de Pereira e Antunes, 2007 
MOURÃO, R.C. et al. Processamento do milho na alimentação de ruminantes. PUBVET, Londrina, V. 6, N. 5, Ed. 192, Art. 1292, 2012.

\section{CARBOIDRATOS NÃO ESTRUTURAIS NA DIETA DE RUMINANTES}

O grupo de carboidratos não estruturais é constituído pelos açúcares e amido, sendo assim classificados por estarem presentes no conteúdo celular e serem fontes de energia prontamente disponíveis ou de reserva para a planta (De Visser, 1993; Chesson e Forsberg, 1997). Os carboidratos estruturais, por outro lado, compõem a parede celular dos vegetais, o arcabouço celular fibroso que garante resistência física à célula vegetal. A celulose e a hemicelulose são os dois principais carboidratos estruturais das plantas (Antunes e Rodriguez, 2006). A pectina é um polissacarídeo amorfo, contido na parede celular, portanto, caracterizada como carboidrato estrutural. Porém, ela também é classificada como carboidrato não fibroso, no aspecto nutricional, por ser totalmente solúvel em detergente neutro e ser rápida e extensamente degradável pelos microorganismos ruminais (Van Soest, 1994).

Os carboidratos não estruturais, por sua vez, são compostos por moléculas de monossacarídeos de 5 ou 6 átomos de carbono. As pentoses mais comumente encontradas são a ribose, arabinose e xilose, enquanto as hexoses mais comuns são a glicose, galactose e frutose (Antunes e Rodriguez, 2006). Entre estes monossacarídeos, a glicose é o mais importante para a nutrição de ruminantes, sendo constituinte de compostos energéticos de extrema relevância do ponto de vista nutricional, como o amido, presente nos grãos de cereais, tubérculos e raízes.

\section{CARACTERÍSTICAS DO AMIDO}

O amido é um polissacarídeo de elevado peso molecular e é sintetizado pelas plantas superiores com função de reserva energética nos períodos de dormência, germinação de grãos, crescimento e rebrota (Wang et al., 1998). As plantas armazenam amido nas raízes, caules, tubérculos e grãos. Os grãos são as principais fontes de amido na alimentação humana e animal, podendo conter até $80 \%$ do seu peso seco em amido (Buléon et al., 1997). 
MOURÃO, R.C. et al. Processamento do milho na alimentação de ruminantes. PUBVET, Londrina, V. 6, N. 5, Ed. 192, Art. 1292, 2012.

Quimicamente, o amido é formado por dois polímeros de glicose, a amilose e a amilopectina (French, 1973; Wang et al., 1998). Estes polímeros diferenciamse entre si quanto ao tipo de estrutura química, tamanho da molécula e quanto às propriedades químicas.

A amilose é um polímero longo e relativamente linear, formado por moléculas de D-glicose, com cerca de $99 \%$ das ligações $\propto-1-4$. Por outro lado, a amilopectina é uma molécula maior que a amilose, mais insolúvel, formada por moléculas de D-glicose, com ligações $\propto-1-4$, com ramificações $\propto-1-6$ (Lehninger, 1998).

Além da amilose e da amilopectina, os grânulos de amido são compostos por lipídios, proteínas e minerais, cuja composição é dependente da espécie e da parte da planta onde se encontram (Rooney e Pflugfelder, 1986). De maneira geral, a amilose e a amilopectina representam de 98 a $99 \%$ dos grânulos de amido.

Diversos tipos de processamento são aplicados aos grãos de cereais com a finalidade de romper as pontes de hidrogênio dentro dos grânulos de amido, melhorando a sua capacidade de hidratação. Dessa forma, o amido torna-se mais susceptível à digestão enzimática (Flint e Forsberg, 1995). A digestibilidade do amido do grão de milho é limitada também pela matriz protéica que encapsula grânulos de amido e pela natureza compacta do amido em si, particularmente na parte do endosperma duro que impede a colonização microbiana e a penetração de enzimas amilolíticas (McAllister et al., 1990). A quebra da matriz proteína pode melhorar a velocidade e a extensão da digestão do amido (Philippeau et al, 1999;. Correa et al, 2002).

\section{PROCESSAMENTO DE GRÃOS}

Muitos tipos de processamentos físicos e químicos estão disponíveis para melhorar a digestibilidade dos grãos e o desempenho dos ruminantes (Owens et al., 1986). De maneira geral, os fundamentos do processamento dos grãos 
MOURÃO, R.C. et al. Processamento do milho na alimentação de ruminantes. PUBVET, Londrina, V. 6, N. 5, Ed. 192, Art. 1292, 2012.

são a melhoria da digestibilidade dos alimentos e/ou a conservação, o isolamento das partes específicas, a melhoria da palatabilidade ou detoxificação dos alimentos (Pond et al., 1995).

O processamento dos grãos de cereais altera ainda o local de digestão do amido no trato digestivo dos ruminantes. Os tratamentos que provocam alterações químicas do amido aumentam consideravelmente a utilização destes grãos em comparação aos processos mecânicos, principalmente em decorrência do aumento da digestibilidade do amido no rúmen (Theurer, 1986); ou seja, o maior efeito do processamento adequado de grãos é a mudança do local de digestão do amido do intestino para o rúmen e o aumento concomitante da porcentagem digerida em ambos os compartimentos. Segundo Theurer et al. (1999) a alteração do padrão de fermentação do milho eleva a produção de propionato no rúmen, aumentando a produção de glicose por gliconeogênese.

Entre os conhecidos métodos de processamento de grãos, podemos diferenciar os processos a seco e os que envolvem a adição de água, frequentemente na forma de vapor e com elevada pressão (Hale, 1973). Podemos citar como exemplos de processos a seco a moagem fina ou grosseira, micronização, tostagem, peletização e laminação. Entre os processos que envolvem a adição de água, destacam-se a laminação a vapor, floculação, expansão e a extrusão. Segundo Theurer (1986), a união dos dois processos, redução do tamanho de partícula e aplicação de vapor, melhora ainda mais a eficiência da digestão dos alimentos processados pelos ruminantes.

No entanto, alguns efeitos adversos podem ser verificados em ruminantes alimentados com dietas de alta densidade energética e à base de grãos processados. Entre eles destacam-se a acidose ruminal (clínica ou sub-clínica), diminuição da digestibilidade da fibra e da ingestão de alimentos (Mc Carthy et al., 1989).

Neste sentido, deve-se atentar para o adequado ajuste da dieta em função dos riscos metabólicos existentes. Geralmente, ao se utilizar estes ingredientes 
MOURÃO, R.C. et al. Processamento do milho na alimentação de ruminantes. PUBVET, Londrina, V. 6, N. 5, Ed. 192, Art. 1292, 2012.

processados, é recomendada a utilização de uma maior proporção de fibra na dieta, já que, com o processamento dos grãos, espera-se um incremento da digestibilidade do amido.

\section{MOAGEM FINA OU GROSSEIRA}

Entre as diferentes formas de apresentação do milho nas dietas de ruminantes, a quirera ou milho quebrado é a mais comum delas, sendo este produto encontrado no mercado a varejo e de simples processamento. Da mesma forma, a moagem fina do grão de milho também é bastante difundida e acessível aos produtores rurais.

A moagem do grão de milho é um processo de diminuição do tamanho de partículas, gerado a partir da força do impacto, corte ou atrito, seguida de peneiramento, que auxilia na padronização do produto, podendo este apresentar aspecto fino ou grosseiro. Do ponto de vista nutricional, pode-se considerar que quanto menor o tamanho das partículas maior o contato do alimento com os microrganismos ruminais e enzimas digestivas, favorecendo a digestão e a absorção. A moagem dos grãos favorece a mistura de ingredientes e promove aumento na qualidade e eficiência dos processos de peletização e extrusão (Barbieri, 1998).

O tamanho das partículas dos alimentos influencia a taxa de passagem do rúmen e altera a sua distribuição dentro do órgão: quanto menor a partícula maior a oportunidade de sua localização na parte dorsal onde a digestão microbiana é menos intensa. Já o fornecimento de grãos de milho inteiros implica em sua locomoção para saco ventral, tendo nesta situação maiorpermanência no interior do órgão (Lucci et al., 2008).

\section{LAMINAÇÃO A SECO}

O processo de laminação consiste na passagem dos grãos entre dois rolos, sob alta pressão, que podem variar em tamanho, tipo de esmagamento e velocidade de passagem. Neste processo, assim como na moagem, os grãos 
MOURÃO, R.C. et al. Processamento do milho na alimentação de ruminantes. PUBVET, Londrina, V. 6, N. 5, Ed. 192, Art. 1292, 2012.

sofrem modificações apenas na sua estrutura física, porém, de forma mais branda.

Este procedimento permite um aumento na digestibilidade ruminal em relação ao grão inteiro, porém, em comparação à moagem, a digestibilidade ruminal é menor. De acordo com Mello Júnior (1991), o uso de concentrados contendo grãos submetidos a este tipo de processamento determina aumento na quantidade de amido que chega ao intestino delgado. $O$ amido, neste caso, pode ser pouco disponível por não sofrer gelatinização e ter reduzida superfície de exposição aos microrganismos ruminais e enzimas digestivas.

\section{LAMINAÇÃO A VAPOR}

$\mathrm{Na}$ laminação a vapor, além do efeito físico sobre os grãos, bastante semelhante ao proporcionado pela laminação a seco, ocorre um aumento da umidade e da temperatura dos grãos, por meio da exposição do milho ao vapor d'água, o que potencializa o efeito da gelatinização do amido. O grau de gelatinização depende da temperatura do processo e do tempo de exposição dos grãos.

De acordo com Pereira e Antunes (2007), antes de serem submetidos à prensa pelos rolos compressores, os grãos são mantidos por 15 a 20 minutos em um condensador, onde recebem o contato do vapor, a uma temperatura de 90 a $95^{\circ} \mathrm{C}$, elevando a sua umidade para concentrações entre 17 e $20 \%$. Em seguida, o milho é direcionado por gravidade aos rolos compressores, localizados abaixo do condicionador, onde ocorre a laminação, gerando grãos de 1,5 a 2,4 mm de espessura. Posteriormente, os grãos laminados e parcialmente gelatinizados são submetidos à secagem.

\section{FLOCULAÇÃO}

Procedimento bastante similar ao anterior, a floculação também consiste na manutenção dos grãos em condensador para injeção de vapor, exposição à laminação pela ação de rolos compressores e secagem final. No entanto, a 
MOURÃO, R.C. et al. Processamento do milho na alimentação de ruminantes. PUBVET, Londrina, V. 6, N. 5, Ed. 192, Art. 1292, 2012.

intensidade da gelatinização e a diminuição do tamanho de partículas fazem com que a floculação seja um processo ainda mais eficiente para aumentar a degradabilidade ruminal e a digestibilidade do milho.

Diferente da laminação a vapor, os grãos são mantidos no condensador por 30 a 40 minutos, a temperatura entre 90 e $105^{\circ} \mathrm{C}$, o que eleva a umidade do milho para 20 a $24 \%$ e intensifica o processo de gelatinização. Além dos rolos laminadores, os grãos passam por um segundo par de rolos, ajustados de forma a comprimirem com maior intensidade os grãos, deixando-os com espessura próxima de 0,9 a 1,1mm (Pereira e Antunes, 2007).

\section{EXPANSÃO}

O processo de expansão foi desenvolvido no final dos anos 80 , no norte da Europa, no intuito de reduzir os altos custos praticados pelas indústrias de ração animal com o processo de extrusão. Além disso, o advindo do processo de expansão possibilitou o alcance dos rígidos padrões de qualidade exigidos pelos órgãos reguladores das indústrias de rações, espelhados em parâmetros físicos e microbiológicos (Fancher et al., 1996).

A expansão é um procedimento térmico, além de físico, que utiliza alta temperatura por um curto espaço de tempo, sendo adotada inicialmente como etapa preliminar à peletização, promovendo a gelatinização do amido e, por conseqüência, a união das partículas e a absorção de umidade no processo seguinte (Rodrigues, 2002). Neste sentido, segundo Lauridsen et al. (1995), o processo de expansão pode reduzir os requerimentos de energia na produção de pellets. De acordo com Heidenreich (1997), em função da correlação entre a gelatinização do amido e a qualidade do pellet, o amido modificado pela expansão pode ser utilizado de forma mais benéfica se comparado com a peletização convencional.

Outros benefícios proporcionados pela expansão têm sido destacados por diversos autores, entre eles a destruição de fatores antinutricionais nos alimentos, eliminação de patógenos e a melhoria na incorporação de gordura 
MOURÃO, R.C. et al. Processamento do milho na alimentação de ruminantes. PUBVET, Londrina, V. 6, N. 5, Ed. 192, Art. 1292, 2012.

no alimento processado (Gill, 1993; Scott et al., 1997). O aumento da digestibilidade e da utilização dos nutrientes é explicada por Rodrigues (2002) em função da alteração da natureza de alguns constituintes dos alimentos. Segundo o autor, a taxa de degradação ruminal do amido é aumentada após a utilização da expansão, porém, a degradação da proteína diminui, aumentando a proteína sobrepassante.

No entanto, o uso desta tecnologia ainda é discreto no Brasil, sendo adotado apenas por algumas empresas do setor de alimentação animal, porém, sem muitos relatos de pesquisas e resultados experimentais consistentes para validar os benefícios do processo nos alimentos disponíveis no país para a produção de ruminantes.

\section{EXTRUSÃO}

A extrusão é um processo termomecânico e contínuo, que combina as operações unitárias como misturar, amassar e modelar, com cocção ou não, para ampliar as possibilidades de elaboração de alimentos básicos ou alternativos, em alimentos de distinta forma, textura, cor e aroma. Seu princípio básico é a conversão de um material sólido em massa fluída pela combinação de umidade, calor, compressão e tensão de cisalhamento, e forçar sua passagem através de uma matriz para formar um produto com características físicas e geométricas pré-determinadas, obtendo-se, assim, a gelatinização do amido e/ou a desnaturação da proteína presente no alimento (Carreiro et al., 2008).

O método da extrusão é muito semelhante ao da expansão. No primeiro, os grãos moídos são condicionados por 30 segundos, a um temperatura de cerca de $150^{\circ} \mathrm{C}$, enquanto que no segundo, emprega-se uma temperatura de 90 a $120^{\circ} \mathrm{C}$, por 2 a 3 segundos, seguida de uma forte compressão sobre o material.

Neste sentido, os benefícios verificados pelas técnicas supracitadas são também similares. Segundo Veloso et al., (2005), apontam-se como vantagens 
MOURÃO, R.C. et al. Processamento do milho na alimentação de ruminantes. PUBVET, Londrina, V. 6, N. 5, Ed. 192, Art. 1292, 2012.

desses processos: gelatinização e hidrólise do amido, redução de microrganismos patogênicos, inativação de fatores antinutricionais termolábeis, melhoria da qualidade sensorial dos alimentos e incremento da digestibilidade de componentes da dieta por aumento da superfície de contato. Algumas empresas do ramo da alimentação animal no Brasil utilizam esta tecnologia para a fabricação de ração comercial, principalmente as que atuam no mercado de produtos para animais de companhia, peixes e demais espécies aquáticas. Apesar do conhecimento de inúmeros benefícios deste método de processamento, o alto custo dos equipamentos é um fator limitante. Produtos de elevado valor agregado, como os citados anteriormente, tendem a aceitar os custos industriais deste processo com maior competitividade.

\section{SILAGEM DE GRÃO ÚMIDO}

A utilização do grão de milho com alta umidade como alimento para animais no Brasil teve início no Paraná, principalmente em criações de suínos. Segundo Kramer e Voorsluys (1991), a denominação alta umidade justifica- se pelo teor de umidade do grão no momento da colheita, sendo recomendado de 35 a $40 \%$ de umidade para uma rápida e favorável fermentação do produto no silo.

Esses autores apontaram algumas vantagens da utilização dessa técnica, entre elas, a minimização das perdas na colheita, a liberação antecipada da área para outras culturas, a redução do tempo gasto com a secagem e das perdas ocasionadas por insetos e roedores durante a armazenagem e a diminuição dos custos do alimento produzido.

Goodrich et al. (1975) afirmaram que o milho colhido com alta umidade poderia passar por fermentação mais longa durante o processo de ensilagem, o que resultaria em maior solubilização e digestibilidade de outros nutrientes além do amido. Assim, ao utilizar grãos de milho com alta umidade, espera-se um aumento na digestibilidade do amido e de outros nutrientes, o que, consequentemente, promoveria melhores desempenhos produtivos, bem como uma melhor eficiência alimentar. 
MOURÃO, R.C. et al. Processamento do milho na alimentação de ruminantes. PUBVET, Londrina, V. 6, N. 5, Ed. 192, Art. 1292, 2012.

\section{GELATINIZAÇÃO DO AMIDO E RETROGRADAÇÃO}

Segundo Singh et al. (2003), gelatinização é o colapso (rompimento) da ordem das moléculas dentro dos grânulos de amido com mudanças de propriedades concomitantes e irreversíveis, como aumento do tamanho granular, fusão de cristais, perda de birrefringência, desenvolvimento de viscosidade e solubilização do amido.

A gelatinização ocorre inicialmente na região amorfa do grânulo (hilo) e segue rapidamente para a periferia (Singh et al., 2003). Em temperatura elevada, as pontes de hidrogênio entre as cadeias de amilose e amilopectina tornam-se mais fracas e são rompidas, promovendo redução da cristalinidade pela destruição da região cristalina, o que possibilita a entrada de água e faz com que o grânulo rompa-se e perca a birrefringência (Lobo e Silva, 2003).

A microscopia óptica é uma ferramenta utilizada para relatar a morfologia do grânulo do amido, bem como sua estrutura e propriedades das pastas, e para auxiliar a visualização das modificações estruturais que ocorrem nos grânulos após modificações químicas e aplicação de energia térmica (Beninca, 2008).

Nas figuras 2 e 3 podem ser observados os grânulos de amido presentes no endosperma dos grãos de milho sem processamento e expandidos, respectivamente, a partir da microscopia eletrônica de varredura. Pode se visualizar na figura 2 os grânulos de amido intactos, enquanto na figura 3 pode-se observar áreas de gelatinização.

A retrogradação do amido é o evento que ocorre quando as moléculas de amido começam a se reassociar em uma estrutura mais ordenada (duplas hélices), tornando-se menos solúveis. Sob condições favoráveis, esta estrutura ordenada pode se desenvolver em forma cristalina, formando partículas de maior tamanho que, por esta razão, podem precipitar (Atwell et al., 1988, citados por Singh et al., 2003). Sabe-se que os cristais começam a tomar forma eventualmente e que este processo é acompanhado por um aumento gradual na rigidez e separação de fase entre polímero e solvente, ou seja, há saída da água ligada às cadeias de amilose. 
MOURÃO, R.C. et al. Processamento do milho na alimentação de ruminantes. PUBVET, Londrina, V. 6, N. 5, Ed. 192, Art. 1292, 2012.

O conteúdo de amilose foi descrito como sendo um dos fatores que influencia a retrogradação do amido. Uma maior proporção de amilose tem sido tradicionalmente ligada a uma maior tendência de ocorrer a retrogradação nos grânulos de amido, porém, a amilopectina, sobretudo em condições de armazenamento refrigerado, também tem um papel importante na retrogradação (Singh et al., 2003)

No entanto, a retrogradação não ocorre sistematicamente nos alimentos processados termicamente e nem reverte completamente os efeitos benéficos da gelatinização do amido. Segundo Beninca (2008), é necessário um melhor entendimento sobre os fatores que controlam o processo, bem como a sua intensidade.

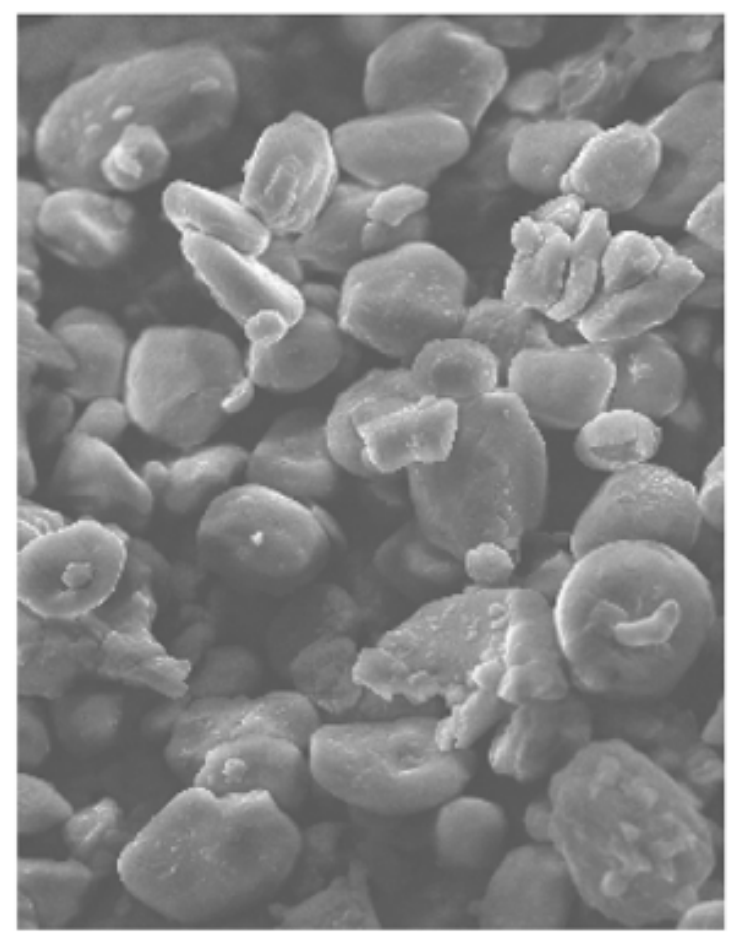

Figura 2 - Grânulos de amido intactos Fonte: Adaptado de Veloso et al., 2005

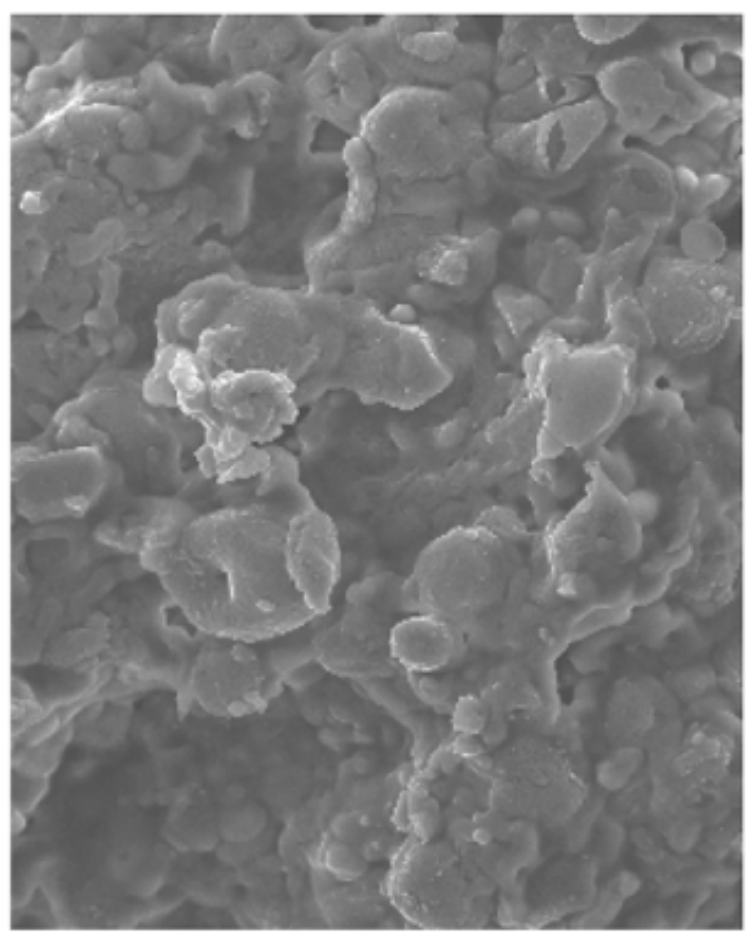

Figura 3 - Grânulos de amido gelatinizados Fonte: Adaptado de Veloso et al., 2005 
MOURÃO, R.C. et al. Processamento do milho na alimentação de ruminantes. PUBVET, Londrina, V. 6, N. 5, Ed. 192, Art. 1292, 2012.

\section{RESULTADOS DE ESTUdOS COM GRÃOS DE MILHO PROCESSADOS}

A maioria dos estudos com diferentes formas de processamento mecânico nos grãos de milho indicam que, quanto mais eficiente o processo de moagem melhores serão os efeitos relacionados à degradabilidade ruminal. Este fato se deve à diminuição do tamanho de partículas, que aumenta a superfície de contato para ação enzimática dos microrganismos ruminais.

$\mathrm{Na}$ tabela 2 pode ser notada a influência do tamanho das partículas do milho processado sobre a degradabilidade potencial e efetiva da matéria seca e proteína bruta. Neste estudo, Lucci et al., (2008) verificou melhores índices para os grãos cujo processamento foi mais intenso.

Tabela 2 - Valores de degradabilidade potencial (dp) e degradabilidade efetiva (de) do milho (MS e PB) nos diferentes tratamentos experimentais. Valores em porcentagens, sendo as taxas de passagem nos cálculos para degradabilidade efetiva $r=0,02$

$\begin{array}{llll}\text { Item } & \text { Milho quebrado Quirera grossa } & \text { Fubá } & \text { Valor de } \mathrm{P}\end{array}$

\begin{tabular}{lcccc}
\hline de (MS) & $35,43^{\mathrm{a}}$ & $63,14^{\mathrm{b}}$ & $71,68^{\mathrm{b}}$ & 0,0001 \\
de (PB) & $43,68^{\mathrm{a}}$ & $50,70^{\mathrm{b}}$ & $55,13^{\mathrm{b}}$ & 0,001 \\
dp (MS) & $46,59^{\mathrm{a}}$ & $76,48^{\mathrm{b}}$ & $84,00^{\mathrm{b}}$ & 0,0001 \\
$\mathrm{dp}(\mathrm{PB})$ & $61,78^{\mathrm{a}}$ & $65,68^{\mathrm{b}}$ & $71,04^{\mathrm{b}}$ & 0,001 \\
\hline Valores & médios com letras distintas na mesma linha indicam diferenças \\
estatisticamente significativas $(p<0,01)$. Fonte: Adaptado de Lucci et al., 2008
\end{tabular}

A moagem fina dos grãos de milho tem resultado em valores de digestibilidade do amido maiores do que na laminação, porém menores que a floculação e que o material colhido precocemente e ensilado (Huntington, 1997). Segundo Butolo (2002), a digestibilidade do milho laminado é maior em relação ao milho inteiro, ao passo que em relação ao grão finamente moído ela é menor, pois a ação enzimática no processo digestivo é menos intensa em função do maior tamanho das partículas.

Na tabela 3 (Owens et al., 1986), podemos verificar valores de digestibilidade do amido dos grãos de milho processados por vários métodos no trato digestório total de ruminantes. Como pode ser visto, a extensão da digestão 
MOURÃO, R.C. et al. Processamento do milho na alimentação de ruminantes. PUBVET, Londrina, V. 6, N. 5, Ed. 192, Art. 1292, 2012.

do amido no rúmen e no trato digestório total foi maior para os grãos finamente moídos em relação aos grãos inteiros e grosseiramente moídos, evidenciando que o suprimento de amido para o intestino delgado é maior quando os grãos são fornecidos aos animais com maiores tamanhos de partículas. Da mesma forma, a digestibilidade ruminal e total dos grãos floculados foi maior do que para os grãos laminados a seco, o que se justifica pelo efeito da gelatinização do amido nos grãos floculados.

Tabela 3 - Valores de digestibilidade de amido dos grãos de milho processados por vários métodos no trato digestivo total dos ruminantes

\begin{tabular}{lcccc}
\hline \multirow{2}{*}{ Método de processamento } & \multirow{4}{c}{$\%$ Digestibilidade } \\
\cline { 2 - 4 } & \multirow{2}{*}{ Rúmen } & \multicolumn{2}{c}{ Intestino } & Trato digestivo \\
\cline { 2 - 4 } total
\end{tabular}

Fonte: Adaptado de Owens et al. (1986)

Huntington (2007) revisou trabalhos publicados entre os anos de 1986 e 1995 e verificou diferenças nos coeficientes de digestibilidade do amido dos grãos de milho, processados por diferentes métodos (Tabela 4). O processamento dos grãos aumentou a degradação ruminal do amido e alterou o sítio de digestão do amido entre os tipos de processamento.

Segundo Owens et al. (1986), a alteração do sítio de digestão do amido, do rúmen para o intestino, pode ser uma desvantagem, já que, em função das perdas energéticas no rúmen, a digestão intestinal é cerca de $42 \%$ mais eficiente. No entanto, o aumento da digestibilidade total do amido nos grãos processados, disponibilizando maior aporte energético aos animais, pode compensar as perdas ruminais por metano e calor (Carateno, 2011). Além disso, segundo o mesmo autor, o processamento pode favorecer a síntese de 
MOURÃO, R.C. et al. Processamento do milho na alimentação de ruminantes. PUBVET, Londrina, V. 6, N. 5, Ed. 192, Art. 1292, 2012.

proteína microbiana no rúmen e consequentemente o fluxo de proteína metabolizável para o intestino.

Tabela 4 - Coeficientes de digestibilidade do amido nos grãos de milho processados por diferentes métodos

\begin{tabular}{|c|c|c|c|c|}
\hline \multirow{3}{*}{$\begin{array}{c}\text { Método de } \\
\text { processamento }\end{array}$} & \multicolumn{4}{|c|}{$\%$ Digestibilidade } \\
\hline & \multirow{2}{*}{$\begin{array}{c}\text { Rumen } \\
\left(\% \text { Consumido }^{1}\right)\end{array}$} & \multicolumn{2}{|c|}{ Pós Rúmen } & \multirow{2}{*}{$\begin{array}{l}\text { Trato total } \\
(\%)\end{array}$} \\
\hline & & $\%$ Consumido $^{2}$ & $\%$ Entrou $^{3}$ & \\
\hline Laminado a seco & 72,6 & 16,2 & 68,9 & 92,2 \\
\hline Floculado & 84,8 & 14,1 & 92,6 & 98,9 \\
\hline Laminado a vapor & 72,1 & 19,0 & 68,2 & 91,2 \\
\hline Silagem grão úmido & 89,9 & 6,3 & 67,8 & 95,3 \\
\hline Grão inteiro & 49,5 & 44,0 & 86,5 & 93,5 \\
\hline
\end{tabular}

${ }_{1}^{1}$ Percentual de amido digerido no rúmen em relação total consumido. ${ }^{2}$ Percentual de amido digerido pós rúmen em relação ao total consumido. ${ }^{3}$ Percentual de amido digerido pós rúmen em relação à quantidade que escapou da degradação ruminal. Fonte: Adaptado de Huntington (1997)

Segundo Owens et al. (1997), para se maximizar a eficiência de utilização de concentrados, grãos mais secos devem ser moídos ao invés de laminados e para um máximo desempenho, o aumento da umidade é desejável. Neste sentido, quando não é possível a adoção de um método de processamento com aumento de umidade em condições de temperatura e pressão elevadas, favorecendo assim a gelatinização do amido, a umidificação do alimento processado fisicamente pode ser uma alternativa para favorecer a atividade microbiana durante a fermentação ruminal.

Na tabela 5 é apresentado estudo de Owens et al. (1997), que avaliaram o efeito da adição de umidade nos grãos de milho moído e laminado sobre o ganho de peso diário (GPD), ingestão de matéria seca (IMS), conversão alimentar (CA) e energia metabolizável (EM) em bovinos confinados. Equações de regressão para o GPD e peso corporal ajustado para EM em função do percentual de umidade de grãos processados revelou que o GPD e a EM alcançariam seu máximo entre 30 e $31 \%$ de umidade. 
MOURÃO, R.C. et al. Processamento do milho na alimentação de ruminantes. PUBVET, Londrina, V. 6, N. 5, Ed. 192, Art. 1292, 2012.

Presumivelmente, o aumento na digestibilidade da MS refletiu na EM, que tendeu a aumentar com o teor de umidade. Foi verificada a redução da ingestão de matéria seca (IMS) com o aumento do teor de umidade o que, segundo Owens et al. (1997), pode ser justificado devido à presença de produtos da fermentação, incluindo ácidos e amidas. Adicionalmente, para o milho moído houve uma melhoria significativa na conversão alimentar com a elevação do teor de umidade (Tabela 5).

Tabela 5 - Mínimos quadrados médios para energia metabolizável do grão de milho (EM), ganho de peso diário (GPD), ingestão de matéria seca (IMS) e conversão alimentar (CA) de bovinos alimentados com grãos de milho em diferentes teores de umidade e processamentos antes do armazenamento

\begin{tabular}{|c|c|c|c|c|c|c|c|}
\hline \multirow[b]{2}{*}{ Teor de umidade (\%) } & \multicolumn{3}{|c|}{ Moído } & \multicolumn{3}{|c|}{ Laminado } & Inteiro \\
\hline & 18 a 22 & 23 a 26 & $>27$ & 18 a 22 & 23 a 26 & $>27$ & 23 a 26 \\
\hline GPD (Kg) & 1,13 & 1,32 & 1,27 & 1,02 & 1,01 & 1,16 & 1,39 \\
\hline IMS (Kg) & $8,82^{b}$ & $9,03^{b}$ & $8,19^{c}$ & $9,04^{c}$ & $8,64^{\mathrm{cd}}$ & $8,29^{d}$ & 9,09 \\
\hline CA & $8,1^{\mathrm{b}}$ & $7,2^{\mathrm{bc}}$ & $6,5^{c}$ & 9,0 & 8,6 & 7,2 & 6,6 \\
\hline EM (Mcal/Kg MS) & $3,07^{c}$ & $3,20^{c}$ & $3,48^{d}$ & 2,91 & 3,00 & 3,29 & 3,31 \\
\hline
\end{tabular}

Médias seguidas de letras distintas na mesma linha diferem entre si $(p<0,05)$. Fonte: Adaptado de Owens et al., 1997

Henrique et al. (2007), avaliando o efeito do processamento do milho na terminação de tourinhos em confinamento, verificaram uma melhoria de 9,7\% na eficiência alimentar para os animais alimentados com silagem de grãos úmidos de milho em relação ao milho em grão seco. No entanto, os mesmos autores não verificaram diferenças nas características de carcaça entre os tratamentos.

Na tabela 6 são apresentados os resultados de estudos realizados no Brasil, compilados por Carateno (2011). Estes estudos avaliaram o efeito da ensilagem dos grãos de milho sobre o consumo de matéria seca (CMS), o ganho de peso diário (GPD) e a eficiência alimentar (GPD/CMS) de bovinos confinados. A superioridade verificada para silagem de grãos úmidos pode ser explicada pela maior degradabilidade ruminal e digestibilidade total do milho 
MOURÃO, R.C. et al. Processamento do milho na alimentação de ruminantes. PUBVET, Londrina, V. 6, N. 5, Ed. 192, Art. 1292, 2012.

submetido a este processamento, em detrimento da moagem, conforme elucidado na tabela 3.

Owens \& Gardner (1999) em revisão sobre o assunto, mostraram que animais alimentados com grãos floculados a vapor ganharam peso mais eficientemente e tiveram carcaça mais pesada comparado àqueles que foram alimentados com grão laminado a seco, com alta umidade ou grão inteiro. De acordo com Theurer et al. (1996), a adição de milho floculado nas dietas de animais de corte, em crescimento ou engorda, tem mostrado consistente aumento na eficiência alimentar através da maior utilização de amido quando comparado ao grão não processado ou laminado.

Tabela 6 - Efeito da utilização do grão úmido e do milho moído fino sobre o consumo de matéria seca (CMS), ganho de peso diário (GPD) e eficiência alimentar (GPD/CMS) de bovinos confinados

\begin{tabular}{lcccc}
\hline \multicolumn{1}{c}{ Referência } & $\begin{array}{c}\text { Teor de ração } \\
(\%)\end{array}$ & $\begin{array}{c}\text { Diferença } \\
\text { no CMS }(\%)\end{array}$ & $\begin{array}{c}\text { Diferença } \\
\text { no GPD (\%) }\end{array}$ & $\begin{array}{c}\text { Diferença } \\
\text { GPD/CMS (\%) }\end{array}$ \\
\hline Silva et al., 2007 & 60 & $-18,00$ & $-1,00$ & $+17,24$ \\
Henrique et al., 2007 & 88 & $-1,77$ & $+7,14$ & $+6,25$ \\
Henrique et al., 2007 & 80 & $-3,60$ & $+5,48$ & $+5,50$ \\
Costa et al., 2002 & 60 & $-6,50$ & $+7,89$ & 15,40 \\
\hline Média & 72 & $-7,46$ & $+4,87$ & $+11,10$ \\
\hline
\end{tabular}

MS - Matéria Seca. Fonte: Adaptado de Carateno (2011)

Carateno (2011), avaliando o efeito do processamento do milho em nove trabalhos com bovinos confinados, verificou diminuição no CMS, aumento no GPD e melhoria na eficiência alimentar a favor do milho floculado em relação à laminação a seco (Tabela 7). A melhor eficiência do milho floculado é justificada pela maior digestibilidade do amido, apresentada nas tabelas 3 e 4. No entanto, Nussio et al. (2003) não verificaram benefícios da floculação do milho em relação à laminação para bezerros. Segundo os autores, apesar de comprovadamente benéfica para bovinos com o rúmen plenamente funcional, este processo não melhora o desempenho de animais mais jovens, na fase pré-desmama, e durante as primeiras semanas pós desmama. 
MOURÃO, R.C. et al. Processamento do milho na alimentação de ruminantes. PUBVET, Londrina, V. 6, N. 5, Ed. 192, Art. 1292, 2012.

Rodrigues (2002), avaliando o efeito da expansão do milho na alimentação de ovinos, observou que o processo de expansão aumentou em 36\% o teor energético do grão, sendo verificados 3,89 Mcal ED / kg de MS para o milho moído e 5,31 Mcal ED / kg de MS para o milho expandido.

Tabela 7 - Efeito da utilização do milho floculado e do milho laminado a seco sobre o consumo de matéria seca (CMS), ganho de peso diário (GPD) e eficiência alimentar (GPD/CMS) de bovinos confinados

\begin{tabular}{lcccc}
\hline \multicolumn{1}{c}{ Referência } & $\begin{array}{c}\text { Concentrado na } \\
\text { ração (\% MS) }\end{array}$ & $\begin{array}{c}\text { Diferença } \\
\text { CMS (\%) }\end{array}$ & $\begin{array}{c}\text { Diferença } \\
\text { GPD (\%) }\end{array}$ & $\begin{array}{c}\text { Diferença } \\
\text { GPD/CMS (\%) }\end{array}$ \\
\hline Barajas e Zinn (1998) & 88,00 & $-9,20$ & $+7,60$ & $+17,20$ \\
Brown et al. (2000) & 90,00 & $-1,20$ & $+17,70$ & $+19,80$ \\
Brown et al. (2000) & 90,00 & 0 & $+8,20$ & $+7,80$ \\
Scott et al. (2003) & 92,50 & 0 & $+3,40$ & $+4,30$ \\
Scott et al. (2003) & 92,50 & 0 & $+10,20$ & $+8,40$ \\
Macken et al. (2004) & 93,00 & $-1,48$ & $+15,20$ & $+16,90$ \\
La Brune et al. (2008) & 92,00 & $+1,00$ & $+17,30$ & $+12,50$ \\
Leibovich et al. (2009) & 97,44 & $-6,32$ & $+1,27$ & $+7,70$ \\
Corrigan et al. (2009) & 92,50 & $-8,91$ & $+0,60$ & $+10,44$ \\
\hline Média & 91,31 & $-2,90$ & $+8,99$ & $+12,17$ \\
\hline
\end{tabular}

MS - Matéria Seca. Fonte: Adaptado de Carateno (2011)

Veloso et al. (2005), notaram aumento significativo na digestibilidade no extrativo não nitrogenado (ENN) após a expansão do milho, efeito provavelmente determinado pela gelatinização do amido (Tabela 8). Foi verificada também a diminuição da proteína digestível (PD). Segundo Van Soest (1994), parte do nitrogênio dos alimentos expandidos poderia estar em forma não utilizável (devido à reação de Maillard) no trato gastrintestinal dos animais.

Em contraste com este estudo, Moreira et al. (1994) encontraram valores médios de PD de $4,2 \%$ no milho, $6,4 \%$ no milho pré-cozido e $4,6 \%$ no milho extrusado, enquanto Mendes (2002) verificou valor da PD de 7,8\% no milho e $8,2 \%$ no milho expandido. Desta forma, apesar da influência da reação de Maillard, sugerida para alimentos expandidos por Van Soest (1994), os 
MOURÃO, R.C. et al. Processamento do milho na alimentação de ruminantes. PUBVET, Londrina, V. 6, N. 5, Ed. 192, Art. 1292, 2012.

resultados obtidos por Veloso et al. (2005) parecem ter sido influenciados pelo processamento adotado neste estudo.

Tabela 8 - Matéria seca digestível (MSD), energia digestível (ED), energia metabolizável (EM), proteína digestível (PD) e extrativos não nitrogenados digestíveis (ENND) do milho moído e do milho expandido, na base de matéria seca

\begin{tabular}{lccc} 
& \multicolumn{2}{c}{ Alimento } & \multirow{2}{*}{ Item } \\
\cline { 2 - 3 } & Milho moído & Milho expandido & \\
\hline MSD (\%) & 87,33 & 85,53 & 5,12 \\
ED $(\mathrm{kcal} / \mathrm{kg})$ & 3680 & 3784 & 5,85 \\
EM (kcal/kg) & 3174 & 3081 & 16,41 \\
PD (\%) & $7,18^{\mathrm{a}}$ & $1,33^{\mathrm{b}}$ & 26,53 \\
ENND (\%) & $68,12^{\mathrm{b}}$ & $76,52^{\mathrm{a}}$ & 0,72 \\
\hline
\end{tabular}

Médias seguidas de letras distintas na mesma linha diferem entre si $(p<0,05)$. Fonte: Adaptado de Veloso et al., 2005

\section{CONSIDERAÇÕES FINAIS}

O processamento promove melhorias significativas na digestibilidade do grão de milho e altera o sítio de digestão do amido, favorecendo a sua degradabilidade ruminal e, consequentemente, a síntese de proteína microbiana e o aporte de proteína metabolizável no intestino.

Os processos de moagem, fina ou grosseira e a laminação a seco contribuem para o aumento da degradabilidade ruminal e digestibilidade total dos grãos, a partir da diminuição do tamanho de partículas e da quebra da matriz protéica presente no pericarpo.

Métodos de processamento com adição de umidade, pressão e temperatura elevadas promovem a gelatinização do amido e são mais eficientes no aumento da digestibilidade do que os métodos de processamento a seco.

A retrogradação é um evento que precisa ser estudado com especial atenção, pois pode prejudicar a digestibilidade do amido após ter sofrido gelatinização. 


\section{REFERÊNCIAS BIBLIOGRÁFICAS}

Antunes, R. C.; Rodriguez, N. M. Metabolismo dos carboidratos não estruturais. In: Berchielli, T. T.; Pires, A. V.; Oliveira, S. G. de. Nutrição de Ruminantes, Jaboticabal:Funep, 2006, 583 p.

Barbieri, P. A. P. Moinhos e misturadores. In: Simpósio do colégio brasileiro de nutrição animal e I Seminário sobre tecnologia de produção de rações. Campinas - SP, Anais... Campinas, p. 81-85, 1998.

Beninca, C. Emprego de técnicas termoanalíticas na análise de amidos nativos e quimicamente modificados de diferentes fontes botânicas. 2008. 76f. Dissertação (Mestrado). Universidade Estadual de Ponta Grossa, Ponta Grossa, PR.

Buléon, A. et al. Starch from A. to C. Plant Physiology. 115:949, 1997.

Butolo, J. E. Qualidade de ingredientes na alimentação animal. Campinas: 2002. 430p.

Carateno, R. Fontes de nitrogênio, níveis de forragem e métodos de processamento de milho em rações para tourinhos da raça Nelore terminados em confinamento. 2011. 104f. Tese (Doutorado). Escola Superior de Agricultura Luiz de Queiroz, Universidade de São Paulo, Piracicaba, São Paulo.

Carreiro, A.; Godoy, A.; Lima, A. C.; Tavares, C.; Lopes, D.; Magalhães, V. A. Alimentos Extrusados. Faculdade de Ciências Farmacêuticas, USP, São Paulo: 2008.

Chesson, A.; Forsberg, C. W. Polysaccharide degradation by rumen microorganisms. In: Hobson, P. N.; Stewart, C. S. (Eds). The Rumen Microbial Ecosystem, $2^{a}$ Ed., London: Blackie Academic and Professional, 1997, p.329-381.

Correa, C. E. S.; R. D. Shaver; M. N. Pereira; J. G. Lauer; K. Kohn. 2002. Relationship between corn vitreousness and ruminal in situ starch degradability. J. Dairy Sci. 85:30083012.

De Visser. Characterization of carbohydrates in concentrates for dairy cows. In: Garnsworthy, P. C.; Cole, D. J. A. (Eds). Recent Advances in Animal Nutrition, 1993. Loughborough: Nottingham University Press, 1993, p.19-38.

Fancher, B. I. Rollins, D.; Trimbbe, B. Feed processing using the annular gap expanded and its impact on poultry performance. Journal Applied Poultry Research. v.5, n.4, p.386-394, 1996.

Flint, H. J.; Forsberg, C.W. Polysaccharide degradation in the rumen: biochemistry and genetics. In: Engelhardt, W. V., et al. (Eds). Ruminant Physiology: Digestion, Metabolism, Growth and Reproduction. Proceedings of the Eighth International Symposium on Ruminant Physiology, 1995. Stuttgart: Enke, 1995, p. 43-70.

French, D. Chemical and physical properties of start. Journal of Animal Science, 37:1048, 1973.

Gill, C. HTST - Equivalent conditioning at lower cost. Feed International. P.23-27, 1993.

Goodrich, R. D.; Byers, F. M.; Meiske, J. C. Influence of moisture content, processing and reconstituition on the fermentation of corn grain. Journal of Animal Science, v.41, n.3, p.876-881, 1975.

Hale, W. H. Influence of processing on the utilization of grains (starch) by ruminants. Journal of Animal Science, 37:1075, 1973.

Henrique, W.; Beltrame Filho, J. A.; Leme, P. R.; Lanna, D. P. D.; Alleoni, G. F.; Coutinho Filho, J. F. D.; Sampaio, A. A. M. Avaliação da silagem de grãos de milho úmido com diferentes 
volumosos para tourinhos em terminação. Desempenho e características de carcaça. Revista Brasileira de Zootecnia, v.36, n.1, p.183-190, 2007.

Henrique, W.; Bose, M. L. V. Utilização de resíduos culturais e de beneficiamento de na alimentação de bovinos: Milho e Sorgo. In: Anais do $6^{\circ}$ simpósio sobre nutrição de bovinos, FEALQ, 1995. Piracicaba, SP, p. 153 - 169.

Heidenreich, E. Benefits and side effects of expanding. In: Expoviga, 1997.

Hoseney, R. C.; Davis, A. B.; Harbers, L. H. Pericarp and endosperm structure of sorghum grain shown by scanning electron microscopy. Cereal Chemistry. v.51, p.553-558, 1974.

Huntington, G. B. Starch utilization by ruminants: from basics to the bunk. Journal of Animal Science, v.75, p.852-867, 1997.

Kramer, J.; Voorsluys, J. L. Silagem de milho úmido, uma opção para gado leiteiro. In: SIMPÓSIO SOBRE NUTRIÇÃO DE BOVINOS, 4., 1991, Piracicaba. Anais... Piracicaba: Fundação de Estudos Agrários Luiz de Queiroz, 1991. p.257-262.

Lauridsen, C. L.; Jensen, J. F. Effects of synthetic antioxidants in feed of different technological treatments on the performance of broilers. Arch. Geflugelkd. V.59, n.1, p.73-83, 1995.

Lehninger, A. L. Princípio de Bioquímica. 4a ed. São Paulo: Savier, 1998. P.105.

Lima, G. J. M. M. Milho e subprodutos na alimentação animal. In: Simpósio sobre ingredientes na alimentação animal. Campinas: Colégio Brasileiro de Nutrição Animal, 2001. Anais... Campinas: Colégio Brasileiro de Nutrição Animal, 2001. p.13-32.

Lobo, A. R.; Silva, G. M. Amido resistente e suas propriedades físico-químicas. Revista de Nutrição. Campinas, v.16, n.2, p.219-226, abr./jun. 2003.

Lucci, C. de S.; Fontolan, V.; Hamilton, T. R.; Klu, R.; Wickbold, V. Processamento de grãos de milho para ruminantes: Digestibilidade aparente e "In Situ". Braz. J. Vet. Res. Anim. Sci., São Paulo, v. 45, n. 1, p. 35-40, 2008.

McAllister, T. A.; K. J. Cheng; L. M. Rode; C. W. Forsberg. 1990. Digestion of barley, maize, and wheat by selected species of ruminal bacteria. Appl. Environ. Microbiol. 56:3146-3153.

Mc Carthy, R. D., et al. Effect of source of protein and carbohydrate on ruminal fermentation and passage of nutrients to the small intestine of lactating cows. Journal of Dairy Science, 72:2002, 1989.

Mello Júnior, C. A. Processamento dos grãos de milho e sorgo visando aumento do valor nutritivo. In: Simpósio sobre nutrição de bovinos, 4, 1991, Anais. Piracicaba, FEALQ, 1991. p.263-283.

Mendes, W. S. Valor nutritivo do milho, sorgo e soja submetidos ou não a diferentes processamentos térmicos para suínos em crescimento. 2002. 49f. Tese (Mestrado). Escola de Veterinária, Universidade Federal de Minas Gerais, Belo Horizonte.

Moreira, I.; Rostagno, H. S.; Coelho, D. T.; et al. Determinação dos coeficientes de digestibilidade, valores energéticos e índices de controle de qualidade do milho e soja integral processadas a calor. Rev. Soc. Bras. Zootec., v.23, p.916-929, 1994.

National Research Council (NRC). Nutrients Requirements of dairy cattle. 7.ed. rev. Washington, 2001. 381p.

Nussio, C. M. B.; Santos, F. A. P.; Zopollatto, M.; Pires, A. V.; Morais, J. B. de. Processamento de Milho (Floculado vs. Laminado a Vapor) e Adição de Monensina para Bezerras Leiteiras, Pré e Pós-Desmama Precoce. Revista Brasileira de Zootecnia, v.32, n.1, p.229-239, 2003.

Owens, F. N.; Gardner, B. A. A review of the impact of feedlot management and nutrition on carcass measurements of feedlot cattle. Proc. A. Society of Animal Science, p.1-18, 1999. 
Owens, F. N.; Secristi, D. S.; Jeff Hill, W.; Gill, D. R. The effect of grain source and grain processing on performance of feedlot cattle: a review. Journal of Animal Science, v.75, p.868-879, 1997.

Owens, F. N.; Zinn, R. A.; Kim, Y. K. Limits to starch digestion in the ruminant small intestine. Journal of Animal Science, 63:1634, 1986.

Paes, M. C. D. Aspectos físicos, químicos e tecnológicos do grão de milho. Circular Técnica, Embrapa, CNPMS, n.75, p.1-6, 2006.

Pereira, L. G. R.; Antunes, R. C. O milho na alimentação de gado de leite. In: IV Simpósio Mineiro de Nutrição de Gado de Leite. Belo Horizonte, MG: Escola de Veterinária, UFMG, 2007. p. 49-70.

Philippeau, C.; F. Le Deschault de Monredon; B. Michalet-Doreau. 1999. Relationship between ruminal starch degradation and the physical characteristics of corn grain. J. Anim. Sci. 77:238-243.

Pomeranz, Y.; C. R. Martin; D. D. Traylor; F. S. Lai. 1984. Corn hardness determination. Cereal Chem. 61:147-150.

Pond, W. G.; Church, D. C.; Pond, K. R. Basic Animal Nutrition and Feeding. $4^{a}$ Ed. New York: John Willey and Sons, 1995, p. 353-364.

Rodrigues, E. N. Digestibilidade aparente de dietas contendo feno de Tifton 85 (Cynodon spp) e níveis crescentes de milho moído e milho expandido em ovinos. 2002. 39 f. Dissertação (Mestrado em Ciência Animal), Escola de Veterinária, Universidade Federal de Minas Gerais.

Rooney, L. W.; Pflugfelder, R. L. Factors affecting starch digestibility with special emphasis on sorghum and corn. Journal of Animal Science, 63:1607, 1986.

Rostagno, H. S.; Albino, L. F. T.; Donzele, J. L.; et al. Tabelas brasileiras para aves e suínos. Composição de alimentos e exigências nutricionais. Viçosa: UFV, 2000. 141p.

Scott, T. A.; Swift, M. L.; Bedford, M. R. The influence of feed milling, enzyme supplementation, and nutrient regimen on broiler chick performance. Journal Applied Poultry Research. v.6, n.4, p.391-398, 1997.

Singh, N.; Singh, J.; Kaur, L.; Sodhi, N. S.; Gill, B. S. Morphological, thermal and rheological properties of starches from different botanical sources. Review. Food Chemistry, v.81, p.219231, 2003.

Theurer, C. B. Grain processing effects on starch utilization by ruminants. Journal of Animal Science, v.63, n.4, 1649-1662, 1986.

Theurer, C. B.; Huber, J. T.; Delgado Elorduy, A. Steam flaking improves starch utilization and milk production parameters. In: CORNELL NUTRITION CONFERENCE FOR FEED MANUFACTURES, 1996, Rochester. Proceedings... Rochester: Cornell University, 1996a. 214p.

Theurer, C. B.; Huber, J. T.; Delgado Elorduy, A. et al. Invited review: Summary of steamflaking corn or sorghum grain for lactating dairy cows. Journal of Dairy Science, v.82, p.1950-1959, 1999.

Valadares Filho, S. C.; Rocha Júnior, V. R.; Capelle, E. R. Tabelas brasileiras de composição de alimentos para bovinos. CQBAL 2.0. Viçosa: Universidade Federal de Viçosa. Suprema Gráfica Ltda, 2002. 297p.

Valente, J. de O. Milho para Silagem: Tecnologias, sistemas e custo de produção. CNPMS, Embrapa, Sete Lagoas, MG. Circular Técnica, n.14, p.85, 1991. 
Van Soest, P. J. Nutritional Ecology of the Ruminant. $2^{a}$ ed. Ithaca: Cornell University Press, 1994. $476 \mathrm{p}$.

Veloso, J. A. F.; Medeiros, S. L. S.; Arouca, C. L. C.; Rodriguez, N. M.; Saliba, E. O. S.; Oliveira, S. G., Composição química, avaliação físico-química e nutricional e efeito da expansão do milho e do farelo de soja para suínos em crescimento. Arq. Bras. Med. Vet. Zootec., v.57, n.5, p.623-633, 2005.

Wang Y.; Bogracheva, T. Y.; Hendley, C. L. Starch: as simple as A, B, C? Journal of Experimental Botany, 49:481, 1998.

Watson, S. A. 1987. Structure and Composition. Pages 53-82 in Corn: Chemistry and Technology. S. A. Watson; E. R. Ramstad, ed. American Association of Cereal Chemists, Inc., St. Paul, MN. 